Original Article

\title{
The relationship between bilateral knee muscle strength and gait performance after stroke: the predictive value for gait performance
}

\author{
Makoto Watanabe ${ }^{1 *}$, Makoto Suzuki ${ }^{1,2)}$, Yuko Sugimura ${ }^{3)}$, Takayuki Kawaguchi ${ }^{1,2)}$, \\ Aki Watanabe ${ }^{1,2)}$, Kazuhiko Shibata ${ }^{2,4)}$, Michinari Fukuda ${ }^{1,2)}$ \\ 1) School of Allied Health Sciences, Kitasato University: 1-15-1 Kitasato, Minami-ku, Sagamihara City, \\ Kanagawa 252-0373, Japan \\ 2) Graduate School of Medical Sciences, Kitasato University, Japan \\ 3) Department of Rehabilitation Medicine, Kawasaki Municipal Tama Hospital, Japan \\ 4) Department of Rehabilitation Medicine, Sagamihara Chuo Hospital, Japan
}

\begin{abstract}
Purpose] The purpose of this study was to assess the relationships between bilateral knee extension strengths and gait performance in subjects with poststroke hemiparesis and to predict gait performance by the paretic and nonparetic knee extension strength. [Subjects and Methods] This was a correlational study in which 238 consecutive inpatients with poststroke hemiparesis were enrolled. Knee extensor muscle strengths in paretic and nonparetic lower limbs were measured with a handheld dynamometer, and the presence or absence of impaired gait was also determined. [Results] The mean strength in the paretic lower limb was $0.90 \mathrm{Nm} / \mathrm{kg}$, and that in the nonparetic lower limb was $1.24 \mathrm{Nm} / \mathrm{kg}$. Discriminant analysis classified the difference between the possibility and impossibility of gait by knee extensor muscle strength (standardized discriminant coefficient: paretic, 1.32; nonparetic, 0.55). Thus, paretic and nonparetic knee extension strengths were integrated in the strength index. A threshold level of 2.0 provided the best balance between positive and negative predictive values for the strength index. [Conclusion] The results indicated that both paretic and nonparetic knee extension strengths were related to gait performance. The strength index deduced from bilateral knee extension strengths may serve as a clinically meaningful index for rehabilitation assessment and training.

Key words: Stroke, Handheld dynamometer, Gait
\end{abstract}

(This article was submitted Jun. 17, 2015, and was accepted Jul. 16, 2015)

\section{INTRODUCTION}

Gait is among the most important functions affected after the occurrence of a stroke ${ }^{1)}$. Three months after suffering a stroke, $25 \%$ of surviving patients remain wheelchairbound, and in $60 \%$ of subjects, walking ability and speed are markedly reduced ${ }^{2}$. One of the main impairments after stroke is reduced muscle strength on the side contralateral to the brain lesion $^{3)}$. The relation between paretic knee muscle strength on the contralateral side and gait ability after a stroke has been investigated in many studies ${ }^{1,3-14)}$. A moderate to strong relation is generally observed between knee muscle strength in the paretic limb and gait performance ${ }^{4-13)}$.

However, muscle strength on the side ipsilateral to the lesion can also be affected after stroke ${ }^{3,15)}$. Harris et al. ${ }^{15)}$ suggested that the development of ipsilateral muscle weakness

*Corresponding author. Makoto Watanabe (E-mail: mwat@ ahs.kitasato-u.ac.jp)

C2015 The Society of Physical Therapy Science. Published by IPEC Inc. This is an open-access article distributed under the terms of the Creative Commons Attribution Non-Commercial No Derivatives (by-ncnd) License $<$ http://creativecommons.org/licenses/by-nc-nd/3.0/>. was associated with immobility after stroke and weight loss due to swallowing difficulty and nutritional insufficiency. In addition, throughout the aging process, older people demonstrate an overall decline in muscle mass caused not by stroke but by aging ${ }^{16-18)}$. This generalized loss of skeletal muscle is considered a major factor leading to the development of impairment in muscle strength for older adults ${ }^{18)}$. Regardless of the occurrence of stroke, lower limb weakness has been identified as an important risk factor for walking in older adults ${ }^{19-22)}$. Muscle weakness in the bilateral lower limbs caused by aging may have already been increasing before a stroke ${ }^{23)}$. Thus, paretic and nonparetic lower limb weakness of older stroke patients is complex as a result of the multidimensionality of the challenges caused both by stroke and aging ${ }^{24,25)}$. This muscle weakness associated with aging is most obvious in areas such as Japan, the United States, and Europe, which have dramatically aging populations ${ }^{26-28)}$

Very few studies have assessed the contribution of strength in nonparetic lower limbs to gait performance ${ }^{1,3,29-32)}$. Furthermore, the findings are controversial: three studies ${ }^{1,29,31)}$ reported no significant relation between knee muscle strength in the nonparetic lower limb and gait performance, whereas a further three found a significant relation ${ }^{3,30,32)}$. The association between strength and functions may be curvilinear; 
a critical amount of strength is needed for "normal" performance of specific activities ${ }^{33)}$. Above this threshold level of strength, further increases will not enhance performance of the task. Below the threshold, there should, theoretically, be a stronger relation between strength change and change in performance.

A major aim of stroke rehabilitation is optimization of the recovery of muscle strength to regain walking ability ${ }^{34-37)}$. However, the relation between strength in the nonparetic lower limb and gait performance has attracted much less attention, and the results are conflicting. As the threshold level of strength to predict walking independently is unknown in older stroke patients, it is difficult to predict the level of muscle strength that allows independent walking in older patients with hemiparesis. If bilateral knee muscle strength could be used to predict independent walking, training to regain gait performance would become more evidence-based in aging societies.

Therefore, this study was designed to assess the relations between bilateral knee extension strengths and gait performance in older subjects with poststroke hemiparesis and to predict gait performance by both paretic and nonparetic knee extension strength. Taking into consideration for previous studies on knee extension strength and walking ability $3,30,32$, we hypothesized that there is a significant relationship between bilateral knee extensor strength and gait performance and that both paretic and nonparetic lower limb strength could be used to predict independent walking in older stroke patients. To our knowledge, this is the first study to demonstrate the predictive values of both paretic and nonparetic lower limb strength with respect to gait independency.

\section{SUBJECTS AND METHODS}

The eligibility criteria included hemiplegia of the lower extremities, absence of severe consciousness disorder, ability to sit up with a backrest for more than 30 minutes, ability to push against a dynamometer with the nonparetic lower limb after physical guidance, a period of less than 2 months since the stroke event, absence of severe cardiorespiratory insufficiency, and willingness to participate in the study.

The average value and standard deviation (SD) of normalized knee extensor strength in 20 patients with poststroke hemiplegia were assessed to determine the sample size. There is a strong relation between force as measured by equipment and body weight in strength measurements ${ }^{23)}$. The variability (relative dispersion) of the force scores was reduced by normalization against body weight. Thus, the torques $(\mathrm{Nm})$ determined by force $(\mathrm{N})$ and lower leg length (m) were normalized by the ratio of body weight $(\mathrm{Nm} / \mathrm{kg})$ to predict gait ability by strength measurement. The average normalized knee extensor strength in the nonparetic lower limb of the 20 subjects was 1.33 newton-meters $/ \mathrm{kg}(\mathrm{Nm} /$ $\mathrm{kg}$; SD, $0.37 \mathrm{Nm} / \mathrm{kg}$ ). For the 9 subjects who could walk independently, it was $1.51 \mathrm{Nm} / \mathrm{kg}(\mathrm{SD}, 0.37 \mathrm{Nm} / \mathrm{kg}$ ), and for the 11 subjects who required assistance, it was $1.18 \mathrm{Nm} / \mathrm{kg}$ $(\mathrm{SD}, 0.40 \mathrm{Nm} / \mathrm{kg}$ ). Five percent of the average normalized knee extensor strength for the 9 subjects who could walk was $0.08 \mathrm{Nm} / \mathrm{kg}$ ( $8 \%$ difference), and the standard effect size was 0.30 . Sample size was based on a desired $90 \%$ statistical power to detect an $8 \%$ difference in normalized knee extensor muscle strength against body weight $(\mathrm{Nm} / \mathrm{kg})$, with a two-sided $\alpha$ of $5 \%$. A sample size of 234 was derived by insertion of 1-power (0.90), $\alpha(0.05)$, and standard effect size $(0.30)$ values into the Hulley matrix ${ }^{38)}$. The authors therefore planned to recruit about 234 people with poststroke hemiplegia for this study. The study was approved by the Kawasaki Municipal Tama Hospital Institutional Committee on $\mathrm{Hu}-$ man Research. All subjects and their families were briefed about the aims of the study and the testing procedure prior to participation. Written informed consent was obtained from each subject. This study was performed in accordance with the Declaration of Helsinki.

Knee extension strength was assessed with a $\mu$ Tas MT-1 handheld dynamometer (ANIMA, Tokyo, Japan). The dynamometer pad is $55 \times 55 \mathrm{~mm}$, and its front side is curved to fit the shape of the areas to be measured on the extremities. The measurement range of this dynamometer is 0.1 to $999.9 \mathrm{~N}$, with a recording interval of $0.1 \mathrm{~N}$. A handheld dynamometer may be used to quantify maximal strength and may offer several advantages over free weights, including ease of transport, time efficiency, and low cost. The intraclass correlation coefficients, used to characterize the reliability of the strength tests using the handheld dynamometer, ranged from 0.84 to 0.99 , which is considered good ${ }^{39,40)}$. Furthermore, use of a handheld dynamometer provides a reliable and valid means of measuring muscle strength in patients with brain damage ${ }^{41-44)}$.

Prior to strength testing, the tester took the subject's leg and guided it in the appropriate direction in accordance with the testing protocol to familiarize the subject with the feeling of pushing against the dynamometer. Strength of the knee extensor muscles was then assessed bilaterally using the $\mu$ Tas MT-1. For knee extensor assessment, subjects were seated in a hard chair with their knees flexed $90^{\circ}$ and their arms on their thighs. The dynamometer was placed perpendicular to the leg just above the malleoli. During all tests, the dynamometer was kept stable by the examiner using both hands and/or the subject's leg and was fixed by a belt to keep the knee flexed $90^{\circ}$. Subjects were told to push against the dynamometer by attempting to straighten their leg. They were asked to build force gradually to a maximum voluntary effort. They then maintained maximum effort for 5 additional seconds. Throughout the session, each subject was given consistent verbal encouragement. The limb used to start the testing was randomized.

Gait ability was precisely defined by the Functional Independence Measure (FIM) locomotion item ${ }^{45)}$. The FIM locomotion item was chosen because of its widespread use at rehabilitation facilities and ease of scoring. In this study, when the FIM locomotion item score of a subject was 6 points or more (modified independence, in which the use of a cane and orthosis was accepted for 50-m gait, or complete independence), the subject was considered to be able to walk.

To determine the association between normalized knee extensor muscle strength in paretic and strength in the nonparetic lower limb, Pearson correlation coefficients was used. Then, patients were classified into 2 groups: 
Table 1. Characteristics of patients satisfying the eligibility criteria $(n=238)$

\begin{tabular}{lc}
\hline Age (y) & $70.9 \pm 10.5$ \\
Gender (n) & 138 \\
Men & 100 \\
Women & \\
Diagnosis (n) & 196 \\
$\quad$ Infarction & 42 \\
Hemorrhage & $8.2 \pm 6.9$ \\
Time post stroke at assessment (d) & \\
Paralysis side (n) & 125 \\
$\quad$ Right & 113 \\
$\quad$ Left & \\
Sensory disturbance (n) & 87 \\
Tactile sense & 19 \\
Deep sense & 37 \\
Ataxia (n) & 33 \\
Aphasia (n) & 24 \\
Unilateral spatial neglect (n) & $0.39 \pm 0.04$ \\
Lower leg length (m) & $52.4 \pm 40.7$ \\
Knee extensor muscle strength (Nm) & \\
\hline Values are shown as the mean $\pm \mathrm{SD}$ &
\end{tabular}

those who scored 6 points or more for the FIM locomotion item and those who scored less than 6 points. Discriminant analysis was performed to identify the combination of knee extension strength of both limbs that discriminates best between possibility and impossibility of gait and to clarify the contribution of the paretic and nonparetic lower limbs to gait performance. After discriminant analysis, paretic and nonparetic knee extension strengths, adjusted by the degree of a standardized discriminant coefficient, were integrated in the strength index. The strength index was modeled as a simple regression, and parameter estimates were assessed for goodness of fit to the model: strength index $=\beta_{1} X+\beta_{2}$ $Y\left(\beta_{1}\right.$, standardized discriminant coefficient of paretic lower limb; $X$, normalized knee extension strength of paretic lower limb; $\beta_{2}$, standardized discriminant coefficient of nonparetic lower limb; $Y$, normalized knee extension strength of nonparetic lower limb). The threshold level for prediction of independence was judged as the point where both the negative and positive predictive values were high $^{46-48)}$. All statistical procedures were carried out using SPSS software. A value of $\mathrm{p}<0.05$ was considered statistically significant.

\section{RESULTS}

Between January 2005 and January 2009, 238 consecutive stroke inpatients from Kawasaki Municipal Tama Hospital (Kanagawa, Japan) were enrolled in the present study. Stroke was diagnosed according to the World Health Organization definition ${ }^{49}$. Characteristics of patients who met the inclusion criteria are presented in Table 1. The mean age of participants was 70.9 years (SD, 10.5 years). There were 138

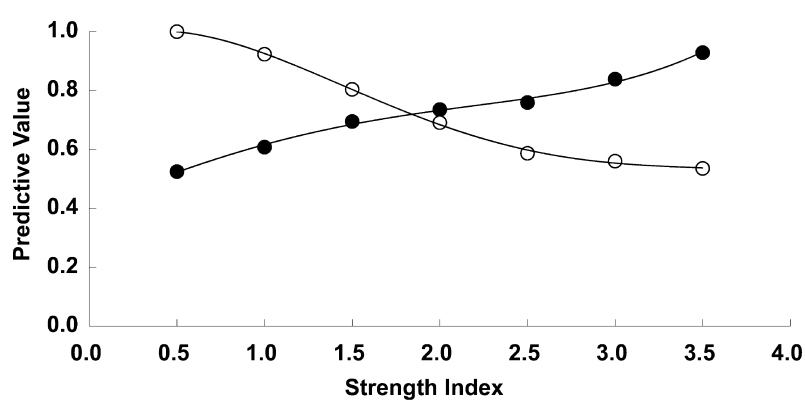

Fig. 1. Prediction of gait performance by predictive value curve The threshold level for prediction of independence was judged as the point where both the negative (open symbols) and positive predictive values (filled symbols) were high. The curve for the negative and positive predictive values indicated that a strength index of 2.0 would provide the best balance for gait performance (positive predictive value, 0.74; negative predictive value, 0.69).

males and 100 females. Of them, 196 and 42 were diagnosed with cerebral infarction and cerebral hemorrhage, respectively, 125 patients had right hemiplegia, and 113 patients had left hemiplegia. The average time since stroke event was 8.2 days (SD, 6.9 days). Mean body weight was $57.6 \mathrm{~kg}$ $(\mathrm{SD}, 11.6 \mathrm{~kg})$. Strength of the knee extensor muscles in the paretic lower limb of the 238 subjects in this study ranged from 0.00 to $321.0 \mathrm{Nm}$ (average, 52.4; SD, $40.7 \mathrm{Nm}$ ). That in the nonparetic lower limb ranged from 7.1 to $336.0 \mathrm{Nm}$ (average, 72.6; SD, $39.9 \mathrm{Nm}$ ). Strength of the normalized knee extensor muscles in the paretic lower limb ranged from 0.00 to $3.82 \mathrm{Nm} / \mathrm{kg}$ (average, $0.90 ; \mathrm{SD}, 0.62 \mathrm{Nm} / \mathrm{kg}$ ). That in the nonparetic lower limb ranged from 0.10 to $4.00 \mathrm{Nm} / \mathrm{kg}$ (average, 1.24; SD, $0.58 \mathrm{Nm} / \mathrm{kg}$ ). The correlation coefficient (r) between normalized knee extensor muscle strength in the paretic lower limb and that in the nonparetic lower limb was 0.73 (Pearson correlation coefficient, $\mathrm{p}<0.0001$ ).

Discriminant analysis was carried out to determine which paretic and nonparetic knee extension strength had a weighted impact on differentiating between the ability and inability to walk. The discriminant analysis classified the difference between the ability and inability to walk (eigenvalue, 0.49; Wilks' lambda, 0.67; $\chi^{2}, 93.85 ; \mathrm{df}, 2 ; \mathrm{p}<0.0001$ ). Two variables contributed to classification of the ability of stroke patients to walk, which was performed with a standardized discriminant coefficient (knee extensor muscle strength in the paretic lower limb, 1.32; that in the nonparetic lower limb, 0.55). Thus, paretic and nonparetic knee extension strengths were integrated in the strength index: strength index $=1.32 X+0.55 Y$, where $X$ is the normalized knee extension strength in the paretic lower limb and $Y$ is the normalized knee extension strength in nonparetic lower limb. After discriminant analysis, the threshold level for prediction of independence was judged as the point where both the negative and positive predictive values were high. A threshold level of 2.0 provided the best balance between positive and negative predictive values for the strength index (Fig. 1). 


\section{DISCUSSION}

In the present study, a relation between both paretic and nonparetic lower limb strength and gait performance was discovered. Our results indicated that (a) the paretic lower limb strength was correlated with the nonparetic lower limb strength, (b) both the paretic and nonparetic knee extension strengths were predictors of gait performance in older patients with poststroke hemiparesis, (c) the paretic knee extension strength affected gait performance more than the nonparetic strength, and (d) the strength indices of the paretic and nonparetic strengths combined with the weighted impact for gait performance could predict gait performance. A strength index of 2.0, meaning that the prediction of gait performance was deduced from the bilateral knee extension strengths, provides the best balance between positive and negative predictive values. About $75 \%$ of patients with a strength index of more than 2.0 could walk independently. However, $70 \%$ of patients with a strength index of 2.0 or less could not walk independently. A previous study suggested that there was a moderate to strong relation between paretic knee extension strength and gait performance ${ }^{4-13)}$, whereas the relation between nonparetic knee extension strength and gait performance was controversial ${ }^{1,3,29-32)}$. However, the abovementioned studies recruited subjects who could walk without supervision or physical assistance and assessed gait speed as gait performance. An additional new observation in the present study was that both the paretic and nonparetic lower limb strengths affected the ability to walk independently. In our study, the predictive value of combined bilateral knee extension strength for gait independency was clearly demonstrated.

Moreover, we provided evidence indicating that paretic lower limb strength is correlated with nonparetic lower limb strength in this study. Throughout the aging process, people demonstrate an overall decline in muscle mass ${ }^{17}$. This generalized loss of skeletal muscle is considered a major factor leading to the development of impairments in muscle strength for older adults ${ }^{18)}$. This muscle weakness associated with aging is obvious in regions such as Japan, the United States, and Europe, where society is dramatically aging ${ }^{26-28)}$. Our results implied that throughout the aging process, older people demonstrate an overall decline in muscle mass caused not by stroke but by aging.

Although progressive resistance training is an appropriate intervention and assessment for improving gait performance and bilateral lower limb strength in older people with poststroke hemiparesis, comparatively little research has focused on the training effect of combined paretic and nonparetic lower limbs of older patients with stroke ${ }^{50)}$. Our study demonstrated the threshold level of the strength index for subjects with poststroke hemiparesis who could ambulate independently. Therefore, the period required to reach the threshold level in resistance training programs may be estimated by further research. In the future, a prospective cohort study is necessary to identify predictors of recovery of independent gait ability after stroke. In addition, isometric evaluation with a handheld dynamometer utilizes a mode of contraction different from that used in training, as isotonic contraction is most commonly used for exercise training.
Thus, use of a handheld dynamometer is limited by lack of specific training. Future studies need to assess whether handheld dynamometers can measure changes in strength after resistance training with the same precision as those measured by isotonic testing.

Engardt et al. ${ }^{51)}$ noted that patients learned to use the nonparetic leg to compensate for the weakness of the paretic leg in the early phase of rehabilitation. In previous studies, patients might have already learned to use the nonparetic leg to compensate for the weakness of the paretic leg in their gait because a long period had passed since the onset of stroke $^{1,3,29-32)}$. It is still difficult to predict the contribution of both the paretic and nonparetic lower limb strengths to gait performance in older patients with poststroke hemiparesis. Thus, we recruited patients in the subacute stage of stroke. However, about $25 \%$ of patients with a strength index of more than 2.0 could not walk independently. When patients with a knee extension strength over the threshold level are unable to walk independently, learning to use the nonparetic and paretic legs might be a useful strategy for the patient to adopt. Activities of daily living are considered behavioral chains of component actions; such chains have been learned and performed since childhood ${ }^{52)}$. A patient with hemiplegia cannot walk by means of the behavioral chains used by a healthy person and thus has to learn new behavioral chains to walk independently. There is a growing body of evidence indicating that locomotor treadmill training with partial body-weight support may be an effective method of improving gait quality in the acute stage of stroke $\mathrm{s}^{53,54)}$. The intensity of resistance training and skill training can be decided by the threshold level of strength determined in this study. Future studies are needed to assess whether changes in muscle strength measured using a handheld dynamometer can reflect the ability of a subject to perform activities of daily life after resistance and skill training.

It has been reported that stroke patients cannot perform at higher angular velocities due to spastic antagonist restraints ${ }^{55)}$. However, isometric strength has been shown not to be affected by antagonist muscle spasticity ${ }^{56}$. Our investigation evaluated the relationship between isometric bilateral knee extension strength and gait performance; as a result, antagonist muscle spasticity would have had little effect on agonist muscle strength. However, because spasticity of knee extensor and flexor muscles in stroke patients was not examined in this study, further research is needed to investigate the relationship between lower limb strength and spasticity and gait performance.

\section{ACKNOWLEDGEMENTS}

The authors acknowledge Yukiko Kimizuka and Megumi Miyamoto for assistance with data collection in this study. This work was supported by a grant from the Policy-based Medical Services Foundation.

\section{REFERENCES}

1) Flansbjer UB, Downham D, Lexell J: Knee muscle strength, gait performance, and perceived participation after stroke. Arch Phys Med Rehabil, 2006, 87: 974-980. [Medline] [CrossRef] 
2) Wade DT, Wood VA, Heller A, et al.: Walking after stroke. Measurement and recovery over the first 3 months. Scand J Rehabil Med, 1987, 19: 2530. [Medline]

3) Kim CM, Eng JJ: The relationship of lower-extremity muscle torque to locomotor performance in people with stroke. Phys Ther, 2003, 83: 49-57. [Medline]

4) Keenan MA, Perry J, Jordan C: Factors affecting balance and ambulation following stroke. Clin Orthop Relat Res, 1984, (182): 165-171. [Medline]

5) Bohannon RW, Andrews AW: Correlation of knee extensor muscle torque and spasticity with gait speed in patients with stroke. Arch Phys Med Rehabil, 1990, 71: 330-333. [Medline]

6) Bohannon RW, Warren ME, Cogman KA: Motor variables correlated with the hand-to-mouth maneuver in stroke patients. Arch Phys Med Rehabil, 1991, 72: 682-684. [Medline]

7) Lindmark B, Hamrin E: Relation between gait speed, knee muscle torque and motor scores in post-stroke patients. Scand J Caring Sci, 1995, 9: 195 202. [Medline] [CrossRef]

8) Davies JM, Mayston MJ, Newham DJ: Electrical and mechanical output of the knee muscles during isometric and isokinetic activity in stroke and healthy adults. Disabil Rehabil, 1996, 18: 83-90. [Medline] [CrossRef]

9) Mayo NE, Wood-Dauphinee S, Ahmed S, et al.: Disablement following stroke. Disabil Rehabil, 1999, 21: 258-268. [Medline] [CrossRef]

10) Nadeau S, Arsenault AB, Gravel D, et al.: Analysis of the clinical factors determining natural and maximal gait speeds in adults with a stroke. Am J Phys Med Rehabil, 1999, 78: 123-130. [Medline] [CrossRef]

11) Hsu AL, Tang PF, Jan MH: Analysis of impairments influencing gait velocity and asymmetry of hemiplegic patients after mild to moderate stroke. Arch Phys Med Rehabil, 2003, 84: 1185-1193. [Medline] [CrossRef]

12) Canning CG, Ada L, Adams R, et al.: Loss of strength contributes more to physical disability after stroke than loss of dexterity. Clin Rehabil, 2004, 18: 300-308. [Medline] [CrossRef]

13) Lin SI: Motor function and joint position sense in relation to gait performance in chronic stroke patients. Arch Phys Med Rehabil, 2005, 86: 197203. [Medline] [CrossRef]

14) Cho KH, Lee JY, Lee KJ, et al.: Factors related to Gait Function in poststroke patients. J Phys Ther Sci, 2014, 26: 1941-1944. [Medline] [CrossRef]

15) Harris ML, Polkey MI, Bath PM, et al.: Quadriceps muscle weakness following acute hemiplegic stroke. Clin Rehabil, 2001, 15: 274-281. [Medline] [CrossRef]

16) Sato $T$, Akatsuka H, Kito $K$, et al.: Age changes in size and number of muscle fibers in human minor pectoral muscle. Mech Ageing Dev, 1984 28: 99-109. [Medline] [CrossRef]

17) Lexell J, Taylor CC, Sjöström M: What is the cause of the ageing atrophy? Total number, size and proportion of different fiber types studied in whole vastus lateralis muscle from 15- to 83-year-old men. J Neurol Sci, 1988, 84: 275-294. [Medline] [CrossRef]

18) Janssen I, Heymsfield SB, Ross R: Low relative skeletal muscle mass (sarcopenia) in older persons is associated with functional impairmen and physical disability. J Am Geriatr Soc, 2002, 50: 889-896. [Medline] [CrossRef]

19) Bohannon RW: Standing balance, lower extremity muscle strength, and walking performance of patients referred for physical therapy. Percept Mot Skills, 1995, 80: 379-385. [Medline] [CrossRef]

20) Wolfson L, Judge J, Whipple R, et al.: Strength is a major factor in balance, gait, and the occurrence of falls. J Gerontol A Biol Sci Med Sci, 1995, 50: 64-67. [Medline]

21) Lamoureux EL, Sparrow WA, Murphy A, et al.: The relationship between lower body strength and obstructed gait in community-dwelling older adults. J Am Geriatr Soc, 2002, 50: 468-473. [Medline] [CrossRef]

22) Nakao $H$, Yoshikawa $T$, Mimura $T$, et al.: Influence of lower-extremity muscle force, muscle mass and asymmetry in knee extension force on gait ability in community-dwelling elderly women. J Phys Ther Sci, 2006, 18: 73-79. [CrossRef]

23) Andrews AW, Thomas MW, Bohannon RW: Normative values for isometric muscle force measurements obtained with hand-held dynamometers. Phys Ther, 1996, 76: 248-259. [Medline]

24) Maeda T, Oowatashi A, Kiyama R, et al.: Discrimination of walking ability using knee joint extension muscle strength in stroke patients. J Phys Ther Sci, 2001, 13: 87-91. [CrossRef]

25) Fujita $T$, Iwata M, Fukuda M, et al.: Relationship between lower extremity muscle mass, leg extension strength and muscle power of hemiplegic stroke patients. J Phys Ther Sci, 2011, 23: 277-282. [CrossRef]

26) Okamoto Y: Health care for the elderly in Japan: medicine and welfare in an aging society facing a crisis in long term care. BMJ, 1992, 305: 403 405. [Medline] [CrossRef]
27) Ory M, Kinney Hoffman M, Hawkins M, et al.: Challenging aging stereotypes: strategies for creating a more active society. Am J Prev Med, 2003, 25: 164-171. [Medline] [CrossRef]

28) Franceschi C, Bezrukov V, Blanché H, et al.: Genetics of healthy aging in Europe: the EU-integrated project GEHA (GEnetics of Healthy Aging). Ann N Y Acad Sci, 2007, 1100: 21-45. [Medline] [CrossRef]

29) Nakamura R, Hosokawa T, Tsuji I: Relationship of muscle strength for knee extension to walking capacity in patients with spastic hemiparesis. Tohoku J Exp Med, 1985, 145: 335-340. [Medline] [CrossRef]

30) Suzuki K, Imada G, Iwaya T, et al.: Determinants and predictors of the maximum walking speed during computer-assisted gait training in hemiparetic stroke patients. Arch Phys Med Rehabil, 1999, 80: 179-182. [Medline] [CrossRef]

31) Bohannon RW, Walsh S: Nature, reliability, and predictive value of muscle performance measures in patients with hemiparesis following stroke. Arch Phys Med Rehabil, 1992, 73: 721-725. [Medline]

32) Kligyte I, Lundy-Ekman L, Medeiros JM: [Relationship between lower extremity muscle strength and dynamic balance in people post-stroke]. Medicina (Kaunas), 2003, 39: 122-128. [Medline]

33) Buchner DM, Beresford SA, Larson EB, et al.: Effects of physical activity on health status in older adults. II. Intervention studies. Annu Rev Public Health, 1992, 13: 469-488. [Medline] [CrossRef]

34) Parker CJ, Gladman JR, Drummond AE: The role of leisure in stroke rehabilitation. Disabil Rehabil, 1997, 19: 1-5. [Medline] [CrossRef]

35) Richards CL, Malouin F, Dean C: Gait in stroke: assessment and rehabilitation. Clin Geriatr Med, 1999, 15: 833-855. [Medline]

36) Patten C, Lexell J, Brown HE: Weakness and strength training in persons with poststroke hemiplegia: rationale, method, and efficacy. J Rehabil Res Dev, 2004, 41: 293-312. [Medline] [CrossRef]

37) Bohannon RW: Muscle strength and muscle training after stroke. J Rehabil Med, 2007, 39: 14-20. [Medline] [CrossRef]

38) Hulley SB, Cummings SR: Designing clinical research. Philadelphia: Lippincott Williams \& Wilkins, 1988.

39) Suomi R, Surburg PR, Lecius P: Reliability of isokinetic and isometric measurement of leg strength on men with mental retardation. Arch Phys Med Rehabil, 1993, 74: 848-852. [Medline] [CrossRef]

40) Schaubert KL, Bohannon RW: Reliability and validity of three strength measures obtained from community-dwelling elderly persons. J Strength Cond Res, 2005, 19: 717-720. [Medline]

41) Riddle DL, Finucane SD, Rothstein JM, et al.: Intrasession and intersession reliability of hand-held dynamometer measurements taken on braindamaged patients. Phys Ther, 1989, 69: 182-194. [Medline]

42) Piao C, Yoshimoto N, Shitama H, et al.: Validity and reliability of the measurement of the quardriceps femoris muscle strength with a hand-held dynamometer on the affected side in hemiplegic patients. J UOEH, 2004, 26: 1-11. [Medline]

43) Katoh M, Asuma H: Test-retest reliability of isometric knee extension muscle strength measurement using a hand-held dynamometer and a belt: study of hemiplegic patients. J Phys Ther Sci, 2011, 23: 25-28. [CrossRef]

44) Katoh M, Isozaki K: Reliability of isometric knee extension muscle strength measurements of healthy elderly subjects made with a hand-held dynamometer and a belt. J Phys Ther Sci, 2014, 26: 1855-1859. [Medline] [CrossRef]

45) Chino N, Riu M, Sonoda S, et al.: Nosottyu kanjya no kino hyoka (Japanese). Tokyo: Springer-Verlag Tokyo, 2003.

46) Suzuki M, Yamada S, Omori M, et al.: Development of the upper-body dressing scale for a buttoned shirt: a preliminary correlational study. Am J Phys Med Rehabil, 2008, 87: 740-749. [Medline] [CrossRef]

47) Suzuki M, Yamada S, Inamura A, et al.: Reliability and validity of measurements of knee extension strength obtained from nursing home residents with dementia. Am J Phys Med Rehabil, 2009, 88: 924-933. [Medline] [CrossRef]

48) Suzuki $M$, Kirimoto $H$, Inamura $A$, et al.: The relationship between knee extension strength and lower extremity functions in nursing home residents with dementia. Disabil Rehabil, 2012, 34: 202-209. [Medline] [CrossRef]

49) Special Report WH: Stroke-1989. Recommendations on stroke prevention, diagnosis, and therapy. Report of the WHO Task Force on Stroke and other Cerebrovascular Disorders. Stroke, 1989, 20: 1407-1431. [Medline] [CrossRef]

50) Liu CJ, Latham NK: Progressive resistance strength training for improving physical function in older adults. Cochrane Database Syst Rev, 2009, 8: CD002759. [Medline]

51) Engardt M, Knutsson E, Jonsson $M$, et al.: Dynamic muscle strength training in stroke patients: effects on knee extension torque, electromyographic activity, and motor function. Arch Phys Med Rehabil, 1995, 76: 419-425. 
[Medline] [CrossRef]

52) Alberto PA, Troutman AC: Applied behavior analysis for teachers (for Japanese translation). Tokyo: Bell \& Howell Company, 2003.

53) da Cunha IT Jr, Lim PA, Qureshy H, et al.: Gait outcomes after acute stroke rehabilitation with supported treadmill ambulation training: a randomized controlled pilot study. Arch Phys Med Rehabil, 2002, 83: 1258-1265. [Medline] [CrossRef]

54) McCain KJ, Pollo FE, Baum BS, et al.: Locomotor treadmill training with partial body-weight support before overground gait in adults with acute stroke: a pilot study. Arch Phys Med Rehabil, 2008, 89: 684-691. [Medline] [CrossRef]

55) Knutsson E, Mårtensson A, Gransberg L: Influences of muscle stretch reflexes on voluntary, velocity-controlled movements in spastic paraparesis. Brain, 1997, 120: 1621-1633. [Medline] [CrossRef]

56) Bohannon RW, Larkin PA, Smith MB, et al.: Relationship between static muscle strength deficits and spasticity in stroke patients with hemiparesis. Phys Ther, 1987, 67: 1068-1071. [Medline] 